\title{
Crianças Contaminadas por Chumbo: estudo comparativo sobre desempenho escolar
}

\author{
VERA LÚCIA MESSIAS FIALHO CAPELLINI \\ Professora do Departamento de Educação da Unesp de Bauru \\ verinha@fc.unesp.br \\ OLGA MARIA PIAZENTIN ROLIM RODRIGUES \\ Professora do Departamento de Psicologia da Unesp de Bauru e do Programa de \\ Pós-Graduação em Desenvolvimento e Aprendizagem \\ olgarolim@uol.com.br \\ LÍGIA EBNER MELCHIORI \\ Professora do Departamento de Psicologia da Unesp de Bauru e do Programa de \\ Pós-Graduação em Desenvolvimento e Aprendizagem \\ lmelch@fc.unesp.br \\ TÂNIA GRACY MARTINS DO VALLE \\ Professora do Departamento de Psicologia da Unesp de Bauru e do Programa de \\ Pós-Graduação em Desenvolvimento e Aprendizagem \\ tgvalle@uol.com.br
}

\begin{abstract}
Resumo
Pesquisas mostram que a presença de metais, acima dos níveis permitidos pela legislação, representa riscos para a saúde humana. Crianças são mais vulneráveis aos efeitos do chumbo, que pode causar rebaixamento permanente da inteligência e outros distúrbios associados, como baixo desempenho escolar. O objetivo do estudo foi avaliar o rendimento escolar de crianças contaminadas por chumbo, comparando-o com o daquelas que não estavam contaminadas. Participaram três grupos com 25 crianças cada, de seis a treze anos; o Grupo 1, com crianças contaminadas por chumbo; o Grupo 2, com crianças com chumbo zero comprovado, embora residentes no local da contaminação; e o Grupo 3, com crianças de um bairro com características sociodemográficas semelhantes às do local da contaminação, porém, sem contaminação comprovada. Para a avaliação do rendimento escolar, utilizou-se o Teste de Desempenho Escolar - TDE. Os resultados mostraram melhor desempenho para o Grupo 2 (não contaminadas) e pior para o Grupo 1 (contaminadas).

Palavras-chave: contaminação por chumbo, teste de desempenho escolar, rendimento escolar.
\end{abstract}




\section{Resumen}

Algunas investigaciones demuestran que la presencia de metales por sobre los niveles permitidos por la legislación, representa riesgos para la salud. Los niños son los más vulnerables a los efectos del plomo, que puede ocasionar una disminución permanente de la inteligencia y otros trastornos como rendimiento escolar inferior. El objetivo del estudio fue evaluar el rendimiento escolar de niños contaminados con plomo y compararlo con el de niños no contaminados. Participaron en cada grupo 25 niños con edades entre seis y trece años. El Grupo 1, integrado por niños contaminados. El Grupo 2, con niños con nivel cero de plomo comprobado a pesar de residir en el lugar contaminado y el Grupo 3, con niños de un barrio con características sociodemográficas semejantes a las del lugar contaminado y, sin embargo, sin contaminación comprobada. Para la evaluación del rendimiento escolar se utilizó el Test de Desempeño Escolar (TDE). Los resultados mostraron un mejor desempeño en el Grupo 2 (niños no contaminados) y peor para el Grupo 1 (niños contaminados).

Palabras clave: contaminación con plomo, test de desempeño escolar, rendimiento escolar.

\section{Abstract}

Research shows that the presence of metals above the levels allowed by legislation poses risks to human health. Children are more vulnerable to the effects of lead, which may cause a permanent decrease in intelligence and other associated disorders, such as lower school performance. The objective of this study was to evaluate the school production of leadcontaminated children comparing it to the performance of non-contaminated children. Three groups of 25 children aged 6 to 13, took part, Group 1 being of lead-contaminated children, Group 2 of children with zero proven lead, and Group 3 of children from a neighborhood with social demographic characteristics similar to the contaminated area, yet without proven contamination. For the evaluation of school production the TDE - Teste de Desempenho Escolar (School Production Test) was used. The results indicated that Group 2 had the best performance (non-contaminated) while the worst performance was of those who were contaminated (Group 1).

Key words: lead contamination, school production test, school production. 


\section{INTRODUÇÃO}

O chumbo é o metal mais abundante na crosta terrestre e sua utilização data de épocas pré-históricas (Silbergeld, 1997; Gidlow, 2004). Seus efeitos no organismo já são conhecidos praticamente desde que o homem aprendeu a trabalhar com esse metal (Hipócrates, 600 a.C., mencionou a cólica como uma consequiência do chumbo). $\mathrm{O}$ estudo de Gilfilian (1965, citado por Gomes, 2003) atribuiu a decadência do Império Romano ao uso de condimentos manipulados em vasilhames de chumbo.

Ele é um metal pesado, tóxico, maleável e pobre condutor de eletricidade. É suficientemente mole para ser cortado com uma faca, porém impurezas como o antimônio, arsênio, cobre ou zinco tornam-o muito duro. Apresenta coloração branco-azulada quando recentemente cortado, porém adquire coloração acinzentada quando exposto ao ar. É usado na construção civil, em baterias de ácido, munição, na proteção contra raio $X$, e é parte de ligas metálicas para a produção de soldas, fusíveis, revestimentos de cabos elétricos, materiais antifricção, metais de tipografia, etc. $\mathrm{O}$ chumbo tem o número atômico mais elevado entre todos os elementos estáveis (International..., 1995; Silbergeld, 1997; Mavropoulos, 1999; Gomes, 2003; Gidlow, 2004).

O chumbo é, hoje, considerado um contaminador ambiental. Com o advento da Revolução Industrial, as concentrações do metal no meio ambiente elevaram-se de forma alarmante, principalmente em razão da introdução de compostos orgânicos de chumbo em diversos materiais e equipamentos de uso contínuo (Silbergeld, 1997; Mavropoulos, 1999).

Meireles (1981) afirma que esse mineral é o que mais causa intoxicações e está presente no solo, no ar e na água. As principais fontes de contaminação são as indústrias de baterias automotivas, as chapas de metal semi-acabado, os canos de metal, aditivos em gasolina, munição, indústria de reciclagem de sucata de baterias automotivas para reutilização de chumbo, tintas, soldas de latas, pesticidas, agrotóxicos, etc.

A demanda de chumbo tem sofrido mudanças quanto a sua utilização. Como antidetonante na gasolina e em tintas tem sido proibido por lei em diversos países, porém seu emprego em processos industriais tem aumentado significantemente. Usava-se chumbo na fabricação de canos para condutores de água, na fabricação de revestimento de cabos elétricos, de chapas para pias, cisternas e telhados, na indústria de acumuladores, etc. (Meireles, 1981). 
Segundo Silbergeld (1997), a primeira legislação sobre a proteção de trabalhadores expostos a chumbo foi elaborada em 1883 na Inglaterra, em virtude da morte, em 1882, de diversos empregados de empresas que utilizavam o metal em seus processos produtivos.

A contaminação do solo pode advir de forma natural ou geológica, como também por meio de atividades exercidas pelo homem (mineração, indústria e transporte). Desse modo, os teores de chumbo no solo variam: em regiões próximas às vias de tráfego intenso e indústrias são bem mais elevados que aqueles encontrados em áreas isoladas (Larini, 1993).

Segundo a World Health Organization (1989), a principal forma de dispersão das partículas de chumbo é através do ar (cerca de 20\%); entretanto podem permanecer em suspensão por dias, ser carreadas pela chuva e acumular-se, assim, na água e no solo. Grande concentração do metal ocorre próximo às fontes de descarga; portanto, é maior em grandes metrópoles do que em áreas suburbanas.

Nriagu e Pacyma (1988, citados por Mavropoulos, 1999) estimaram que, a cada ano, um total de 330 mil toneladas de chumbo é despejado diretamente na atmosfera. Somente $4 \%$ dele provém de fontes naturais (emissões vulcânicas, erosão e depósitos naturais).

A produção de baterias chumbo-ácidas representa o segmento industrial responsável pelo maior consumo de chumbo nos países em desenvolvimento. Sua fabricação utiliza tecnologia bastante simples, podendo ser realizada em pequena escala, tornando-se, por conseguinte, atraente para esses países. Em razão de suas propriedades tóxicas e das condições de trabalho prevalentes na maioria dessas indústrias, os trabalhadores desse setor encontram-se freqüentemente expostos a elevadas concentrações desse elemento e, portanto, sujeitos a intoxicação. Por esse motivo, as pesquisas relacionadas à intoxicação por chumbo, que consideraram ser prejudicial à saúde humana níveis no sangue acima de $40 \mu \mathrm{g} / \mathrm{dl}$, foram limitadas quase que exclusivamente às pessoas que trabalhavam diretamente com esse metal (Cordeiro, Lima-Filho, 1995; Araújo, Pivetta, Moreira, 1999).

Os principais efeitos dos compostos de chumbo no sistema nervoso, por exposição crônica, são as encefalopatias que resultam em irritabilidade, cefaléia, tremor muscular, alucinações, perda da memória e da capacidade de concentração. Esses sintomas podem progredir e causar delírios, convulsões, paralisias e coma. Dados experimentais revelam que danos causados pelo chumbo podem afetar funções da memória e do aprendizado em todos os ciclos da vida (Internacional..., 1995; Banks, Ferretti, Shucard, 1997; Moreira, Moreira, 2004). 
Em 1890 foram descobertos os primeiros casos de intoxicação por chumbo em crianças. A relação entre a exposição ao chumbo e o déficit intelectual foi apresentada pela primeira vez num estudo conduzido por Gibson et al. (1892), realizado na Austrália, que envolveu crianças com idade entre onze e treze anos. Entretanto, apenas em 1920 foi formalmente assumido que elas são uma população de risco, e essa contaminação tornou-se, então, um importante problema de saúde pública no mundo (Silbergeld, 1997; Koller et al., 2004). Nos sintomas iniciais, reversíveis, destacam-se dores abdominais, perda de apetite, constipação intestinal, fadiga, distúrbios do sono, diminuição das atividades físicas, irritabilidade, choro imotivado, hiperatividade, baixo rendimento escolar, alterações da memória, anemia, etc. As crianças são especialmente vulneráveis aos efeitos do chumbo, em razão de vários fatores: a) o consumo por quilo de peso é maior do que nos adultos; b) elas colocam objetos sujos na boca com freqüência; c) a absorção de chumbo pelo organismo é maior do que nos adultos; d) por estarem em processo de crescimento, seus órgãos ainda não se desenvolveram completamente; mesmo quantidades relativamente pequenas podem causar distúrbios psicológicos e retardamento mental (Yule, Rutter, 1983; Needleman, Gatsonis, 1990; Stiles, Bellinger, 1993; Bellinger, 1995). Koller e outros (2004) afirmam que as crianças são mais suscetíveis, sobretudo em razão da maior absorção do chumbo pelo trato gastrointestinal. Seu sistema nervoso também é mais vulnerável em relação à população adulta.

Embora na literatura os estudos referentes à toxicidade do chumbo gerem algumas contradições, a gravidade de seus efeitos depende de vários fatores, entre eles a intensidade e o tipo de exposição, a idade dos indivíduos e, também, fatores demográficos e sociais (Silbergeld, 1997). Pesquisas ambientais mais recentes sugerem que, ainda que o tratamento seja providenciado, a eliminação de chumbo do ambiente é extremamente lenta; pode demorar até 10 anos para se efetivar (Malta, Trigo, Cunha, 2000).

Moreira e Moreira (2004) declaram que, apesar de os estudos científicos a respeito da toxicologia do chumbo serem desenvolvidos há mais de um século, ainda são insuficientes as informações acerca dos mecanismos de ação que originam os efeitos tóxicos desse metal. Os resultados da exposição ao chumbo sobre os ossos, o sistema nervoso central e cardiovascular, os rins e o fígado, devem ser estudados em profundidade, bem como as conseqüências na reprodução masculina e feminina, no sistema endócrino e na formação do feto. Também é essencial esclarecer se o chumbo tem efeitos teratogênicos e carcinogênicos em seres humanos. Investigações recentes têm sido conduzidas no mundo todo, e 
apresentam evidências quanto aos efeitos do chumbo, mesmo em pequena quantidade.

Pesquisas da década de 40 tentaram provar que as crianças contaminadas que sobreviviam ficavam com déficits nas funções intelectuais (Bellinger, 1995). Trabalhos associando níveis de chumbo com problemas de comportamento, rebaixamento intelectual e aprendizagem educacional de crianças foram realizados a partir daí (Needleman, 1979; Thatcher et al., 1982; Yule, Rutter, 1983; Harvey, Hamlin, Kumar, 1983). Smith (1985) sugeriu falta de rigor metodológico, chamando a atenção para o papel dos fatores sociais que, no seu entender, não foram devidamente controlados.

Esse autor, após vários estudos epidemiológicos realizados desde 1979, concluiu que as conseqüências no QI, em razão dos baixos níveis de chumbo, eram menores do que quaisquer dos outros fatores estudados; afirmou que o baixo nível de chumbo no sangue estava ligado a déficits leves, em algumas medidas psicométricas, mas com efeitos tão pequenos que era impossível determinar a causa ou se tiveram alguma real significação. A maioria dos danos ocasionados pelo chumbo tinha outras variáveis interferindo, como as condições ambientais decorrentes da pobreza e a falta de estímulos dos pais. Smith (1985) declarou que os pais deveriam se preocupar menos com o nível de chumbo e mais em contar histórias para seus filhos na hora de dormir.

O estudo de Stiles e Bellinger (1993) mostrou correlação entre o nível de contaminação de chumbo no sangue e o desempenho das crianças em vocabulário e compreensão, quando submetidas ao Wechsler Intelligence Scale for Children (WISC). O desempenho cognitivo também piorou, ainda que com índices baixos, quando a exposição era por longos períodos (Tesman, Hills, 1994; Thomson et al., 1989).

Bellinger (1995) afirma também que, mesmo em quantidades relativamente pequenas, o chumbo pode causar rebaixamento permanente da inteligência em crianças, resultando em prejuízos escolares e distúrbios psicológicos. Thacker e outros (1992) lembram que, geralmente, a população mais prejudicada vive em áreas mais pobres, estando exposta não só ao chumbo, mas a condições sociais desfavoráveis.

Banks, Ferretti e Shucard (1997) relataram a diminuição da inteligência como uma das conseqüências do mineral no organismo, e enquanto efeito teratogênico pode acarretar mutação genética. A contaminação por chumbo, chamada comumente de saturnismo, acontece porque o chumbo, material estranho ao organismo humano, não é eliminado espontaneamente, acumulando-se nos ossos, no sangue e no sistema nervoso. 
Em estudo realizado na Iugoslávia por Canfield e outros (2003), que acompanharam crianças por sete anos, foi encontrada correlação entre o nível de chumbo no sangue e o quociente intelectual das crianças de três e cinco anos de idade. Os resultados mostraram declínio da função cognitiva em crianças cujos níveis sanguíneos de chumbo estavam abaixo do nível delimitado pela World Health Organization $(10 \mu \mathrm{g} / \mathrm{dl})$, sugerindo a revisão nas margens de segurança.

Bellinger et al. (2005), ao verificarem a relação entre nível de chumbo no sangue e problemas no desenvolvimento em 74 crianças de quatro a catorze anos, na Índia, observaram que a quantidade do metal não estava associada ao comportamento, mas sim ao atraso no desenvolvimento, constituindo a intoxicação por chumbo um problema significante entre as crianças avaliadas, em razão dos efeitos colaterais.

Vega-Dienstmaier e outros (2006) realizaram uma pesquisa que objetivou verificar a relação entre níveis séricos de chumbo e funções cognitivas em crianças expostas a esse metal, num estudo transversal que incluiu 134 crianças, de seis a oito anos e cinco meses de idade, de três escolas localizadas em El Callao (Peru) e com riscos diferentes de exposição ao chumbo. As avaliações de suas funções cognitivas foram realizadas utilizando-se o Teste Gráfico de Raciocínio e o Teste dos Cubos de Kohs. Os resultados mostraram que os níveis séricos de chumbo foram associados de maneira não-linear com déficits das habilidades cognitivas, especialmente entre os meninos, sendo o raciocínio numérico a área mais afetada.

No Brasil, vários trabalhos (Cordeiro, 1988; Rocha, Horta, 1987; Araújo, Pivetta, Moreira, 1999; Guaiume, 2001; Aceituno, 2002; Campanili, 2002) ilustram os perigos da exposição ao chumbo, sugerindo que o limite de tolerância ambiental da Norma Regulamentadora NR-7/1994 deveria ser reduzido, pois o índice estabelecido é acima dos $10 \mu \mathrm{g} / \mathrm{dl}$, conforme recomendado pela Organização Mundial da Saúde - OMS (São Paulo, 1997).

Os estudos e a política atual dos países em desenvolvimento demonstram que não é o envenenamento por chumbo que se repete na história, mas sim a falta de controle e prevenção da contaminação química, com o que concordamos.

Os trabalhos apresentados (Vega-Dienstmaier et al., 2006; Bellinger et al., 2005; Canfield et al., 2003; Banks, Ferretti, Shucard, 1997; Tesman, Hills, 1994; Thomson et al., 1989; Stiles, Bellinger, 1993; Bellinger, 1995) relataram prejuízos de ordem cognitiva e comportamental, associados à contaminação por chumbo, que podem acarretar desempenho escolar abaixo do esperado. 
A avaliação de desempenho é feita por meio de testes psicométricos que podem avaliar uma ou mais habilidades do conteúdo acadêmico das crianças (Salvia, Ysseldyke, 1991). Geralmente, eles avaliam o rendimento escolar nas áreas de leitura e escrita.

O Teste de Desempenho Escolar (TDE) tem sido usado para avaliar crianças em diversas condições. Dias, Enumo e Azevedo Jr. (2004) utilizaram o TDE para investigar os efeitos de um programa de criatividade sobre o desempenho escolar e cognitivo de alunos com dificuldade de aprendizagem, comparando-os a um grupo-controle. Os resultados indicaram melhora significativa no desempenho escolar do grupo que participou do treinamento.

Fonseca (2003) utilizou o TDE, entre outros instrumentos (Raven, exame clínico neurológico, entrevista com os pais, etc.), e comparou os resultados com o eletroencefalograma de crianças. Observou, ainda, que as potências absolutas delta e, especialmente, alfa foram maiores nas crianças com melhor desempenho no TDE, independentemente da idade, do sexo e da escolaridade materna.

Fonseca e outros (2004) conduziram um estudo tendo por objetivo investigar o desempenho escolar em crianças com epilepsia. Elas foram submetidas ao TDE e comparadas a crianças sadias, pareadas por idade e escolaridade. Foram estudadas as relações entre o TDE e a lateralidade do foco e o número de descargas no eletroencefalograma. As crianças com epilepsia tiveram, de modo significativo, mais freqüentemente do que as sadias, desempenho inferior no subteste de leitura e no escore total.

Zanoti-Jeronymo e Carvalho (2005) estudaram a correlação entre desempenho escolar, autoconceito e avaliação comportamental de filhos de alcoolistas, utilizando o TDE. Considerando que a convivência com pais alcoólatras pode tornar a criança mais vulnerável a esses problemas, o estudo se propôs a avaliar, comparativamente, filhos de alcoolistas e filhos de não-alcoolistas. Participaram dois grupos de crianças, de ambos os sexos, com idades entre 10 e 12 anos. Os resultados mostraram que filhos de alcoólatras tendem a ter um autoconceito mais negativo e um desempenho escolar inferior nas tarefas de leitura e aritmética, quando comparados aos filhos de não-alcoolistas.

Os estudos citados referendam o uso do TDE para avaliar o repertório acadêmico de crianças brasileiras, o que se justifica neste estudo que pretende avaliar o desempenho escolar de crianças contaminadas por chumbo.

A partir da interdição de uma indústria de baterias automotivas, pela Companhia de Tecnologia de Saneamento Ambiental - Cetesb, em função da emissão de partículas de chumbo (fragmentos contendo sal de 162 Estudos em Avaliação Educacional, v. 19, n. 39, jan./abr. 2008 
óxido de chumbo e sulfato de chumbo no ar e a deposição de chumbo metálico no solo) no meio ambiente, acima do permitido, a Secretaria de Estado da Saúde de São Paulo (SES-SP) e a Secretaria Municipal de Saúde de Bauru (SMS-Bauru), em janeiro de 2002, elaboraram um plano para avaliar a exposição da população ao chumbo. Optou-se por estudar as crianças, consideradas o grupo de maior risco. Foram colhidas amostras sangüíneas para dosagem de chumbo em cerca de 820 crianças, de um mês a 12 anos de idade, e estabeleceu-se como limite de intervenção o nível de plumbemia igual ou superior a $10 \mu \mathrm{g} / \mathrm{dl}$, segundo critérios do Centers for Disease Control and Prevention (CDC).

Participaram como parceiros dos serviços públicos: a Faculdade de Medicina de Botucatu da Universidade Estadual Paulista Júlio Mesquita Filho (FMB-Unesp), Faculdade de Ciências (FC-Unesp/Bauru), Faculdade de Odontologia de Bauru da Universidade de São Paulo (FOB-USP) e Hospital de Reabilitação de Anomalias Craniofaciais (HRAC-USP). Seus representantes compõem o Grupo de Estudo e Pesquisa da Intoxicação por Chumbo em Crianças de Bauru (GEPICCB), que desencadeou medidas de investigação clínico-epidemiológica e tratamento das 314 crianças cujos índices de plumbemia indicavam exposição elevada ao metal. Esses resultados nortearam ações de avaliação clínica, laboratorial e radiográfica das crianças (Padula et al., 2006).

O projeto pretendeu responder à questão: a exposição ao chumbo tem efeito sobre o desempenho escolar das crianças contaminadas, em Bauru? Respostas a essa questão poderiam conduzir a ações preventivas e de intervenção. A intervenção precoce é a forma mais eficiente de prevenir ou minimizar os efeitos de deficiências (Erickson, Riemer, 1999; Guralnick, 1997).

A implementação de programas de intervenção está melhorando o desenvolvimento das crianças especiais e de risco. Para conseguir resultados eficazes é importante identificar como, quando e quais programas devem ser utilizados.

O trabalho preventivo com crianças de risco pode ser realizado quando se identifica precocemente a exposição a efeitos teratogênicos, se constata causa genética, ou se estão expostas a condições adversas. Confirmado o risco, a criança deve ser encaminhada para avaliação não só do seu desenvolvimento geral, mas do desempenho intelectual e escolar.

O estudo do impacto do chumbo na saúde humana e no ambiente é determinante para a prevenção de intoxicações na população, associadas ao crescente desenvolvimento industrial e tecnológico, principalmente em países em desenvolvimento, onde os riscos são pouco avaliados e controlados. No Brasil, a carência de estudos e de um banco de Estudos em Avaliação Educacional, v. 19, n. 39, jan./abr. 2008 
informações, com ênfase na contaminação ambiental, principalmente infantil, conduz à necessidade de projetos que possam subsidiar programas de ação preventiva, essenciais para a proteção da saúde física e mental dessa população.

$\mathrm{Na}$ tentativa de contribuir para o entendimento, o controle, a prevenção da exposição ao chumbo e/ou os efeitos da contaminação por esse metal, minimizando os riscos de prejuízos ao desenvolvimento infantil, foi proposto este estudo.

Como objetivos específicos, pretendeu-se avaliar o desempenho escolar de crianças de seis a treze anos contaminadas por chumbo (Grupo 1); comparar o desempenho escolar desse grupo com crianças da mesma faixa etária e região, sem contaminação, comprovada por exame de sangue (Grupo 2); comparar o desempenho escolar dos Grupos 1 e 2 com crianças da mesma faixa etária e condições sociodemográficas semelhantes, porém residentes em local distante ao da fábrica de baterias, não submetidas a exames (Grupo 3).

\section{MÉTODO}

\section{Participantes}

Participaram do estudo 75 crianças, de seis a treze anos, de ambos os sexos, divididas em três grupos. Compuseram o Grupo 1 as 25 primeiras crianças contaminadas por chumbo no sangue (entre 14,40 e $43,82 \mu \mathrm{g} / \mathrm{dl}$ ), encaminhadas para avaliação no projeto "Atendimento emergencial para crianças de zero a 13 anos de idade contaminadas por chumbo" (Rodrigues, 2002). O Grupo 2 era formado por crianças com chumbo zero comprovado, e o Grupo 3 por crianças moradoras em bairro distante da fonte contaminadora, mas nas mesmas condições sociais do bairro das crianças dos Grupos 1 e 2.

A tabela 1 mostra como foram organizados os grupos, considerando a série e a idade. Cada grupo foi composto por seis crianças matriculadas na $1^{\mathrm{a}}$ série, cinco na $2^{\mathrm{a}}$, sete na $3^{\mathrm{a}}$, quatro na $4^{\mathrm{a}}$ e três na $5^{\mathrm{a}}$. 
Tabela 1 - Composição dos grupos por série e idade

\begin{tabular}{ccccccc}
\hline Série & $\mathbf{1}^{\mathbf{a}}$ & $\mathbf{2}^{\mathbf{a}}$ & $\mathbf{3}^{\mathbf{a}}$ & $\mathbf{4}^{\mathbf{a}}$ & $\mathbf{5}^{\mathbf{a}}$ & Total \\
\hline 6 anos & 1 & - & - & - & - & $\mathbf{1}$ \\
7 anos & 5 & 1 & - & - & - & $\mathbf{6}$ \\
8 anos & - & 3 & - & - & - & $\mathbf{3}$ \\
9 anos & - & - & 6 & - & - & $\mathbf{6}$ \\
10 anos & - & - & 1 & 1 & - & $\mathbf{2}$ \\
11 anos & - & 1 & - & 2 & - & $\mathbf{3}$ \\
12 anos & - & - & - & 1 & 2 & $\mathbf{3}$ \\
13 anos & - & - & - & - & 1 & $\mathbf{1}$ \\
\hline Total & $\mathbf{6}$ & $\mathbf{5}$ & $\mathbf{7}$ & $\mathbf{4}$ & $\mathbf{3}$ & $\mathbf{2 5}$ \\
\hline
\end{tabular}

A tabela 2 apresenta a distribuição dos grupos por sexo, ainda que não fosse critério.

Tabela 2 - Caracterização dos participantes quanto ao sexo

\begin{tabular}{cccc}
\hline Sexo & Grupo 1 & Grupo 2 & Grupo 3 \\
\hline Feminino & 11 & 12 & 11 \\
Masculino & 14 & 13 & 14 \\
\hline
\end{tabular}

\section{Local}

A coleta de dados do Grupo 1 aconteceu numa sala de atendimento individual de uma clínica-escola de Psicologia, e a dos Grupos 2 e 3 na sala da coordenação da escola de origem das crianças, para garantir condições semelhantes de aplicação a todos os participantes.

\section{Material}

Foi utilizada a entrevista aplicada aos pais ou responsáveis pela criança, com a finalidade de coletar seus dados sociodemográficos. 
Para a avaliação de desempenho utilizou-se o Teste de Desempenho Escolar - TDE (Stein, 1994). O TDE é um instrumento psicométrico que busca avaliar, de forma objetiva, o desempenho escolar, mais especificamente da escrita, aritmética e leitura, de alunos de $1^{\mathrm{a}}$ a $6^{\mathrm{a}}$ séries do Ensino Fundamental. Ele é composto por três subtestes:

1. Escrita: ditado de 45 palavras em Português, de nomes próprios e palavras isoladas, em ordem crescente de dificuldade ortográfica e adequadas a alunos do Ensino Fundamental.

2. Aritmética: solução oral de problemas e cálculo de operações aritméticas, por escrito, com grau de dificuldade crescente, correspondendo ao conteúdo da série.

3. Leitura: reconhecer, em uma escala de 75 palavras de Língua Portuguesa, palavras isoladas do contexto, levando em consideração a gradação dos fonemas, número de sílabas, grau de familiaridade do vocábulo e padrões silábicos.

Cada um dos subtestes possui uma escala de itens, em ordem crescente de dificuldade, que é apresentada ao examinando, independentemente de sua série, uma vez que ele pode interromper o subteste quando os itens apresentados em determinado nível da escala não forem resolvidos.

O Escore Bruto (EB) de cada subteste e o Escore Bruto Total (EBT) de todo o TDE são convertidos na classificação: superior, médio e inferior, para cada série escolar, e podem então ser utilizados na comparação do desempenho de um indivíduo com outro.

\section{Procedimento}

As crianças do Grupo 1, contaminadas por chumbo, participavam do projeto de extensão "Atendimento emergencial para crianças de zero a 13 anos de idade contaminadas por chumbo" (Rodrigues, 2002), que tinha por objetivo avaliar seu desenvolvimento geral, intelectual, o desempenho escolar e os possíveis efeitos da contaminação ambiental ocorrida em bairros próximos a uma fábrica de baterias automotivas (Simonetti et al., 2004; Padula et al., 2006).

Entre os dados coletados estavam os referentes ao desempenho escolar avaliado pelo TDE. O critério para definição dos sujeitos deste estudo foi analisar os resultados obtidos neste instrumento pelas 25 primeiras crianças contaminadas avaliadas. Com base nas variáveis idade e série dos participantes do Grupo 1, identificou-se 25 crianças que compuseram o Grupo 2, na listagem de crianças dos mesmos bairros, que no exame para plumbemia obtiveram resultado zero, indicando a não 166 
contaminação. As 25 crianças que compuseram o Grupo 3 (com a mesma idade e da mesma série dos demais grupos), ainda que sem a medida de plumbemia, foram identificadas em um bairro distante da fonte contaminadora, porém com características sociodemográficas semelhantes. O objetivo era constituir mais um grupo de controle.

As crianças do Grupo 2 foram avaliadas nas suas escolas de origem, e as do Grupo 3 foram identificadas em uma mesma escola onde os dados foram coletados. Na ocasião da entrevista com os pais ou responsáveis, o termo de consentimento livre e esclarecido foi assinado.

\section{RESULTADOS E DISCUSSÃO}

Este estudo pretendeu avaliar o desempenho escolar, classificandoo como inferior, médio ou superior, a partir do TDE. Foram comparados três grupos de crianças de seis a treze anos: o Grupo 1, contaminadas por chumbo; o Grupo 2, sem contaminação, comprovada por exame de sangue, mas da mesma região; e o Grupo 3 com condições sociodemográficas semelhantes, porém residentes em local distante ao da fábrica de baterias, não submetidas a exames.

A figura 1 mostra o desempenho dos três grupos, considerando a classificação geral no teste. Observa-se que o Grupo 1 apresentou desempenho caracteristicamente inferior; o Grupo 2, predominantemente superior, e o Grupo 3 um desempenho dentro da média. Considerando cada uma das áreas, os dados apontam melhor desempenho para o Grupo 2 (com chumbo zero) em todos os subtestes avaliados. Nota-se que o Grupo 1 , em todas as áreas avaliadas, apresentou maior porcentagem de crianças com baixo desempenho (cerca de 62\%). Também estavam nessa condição $9 \%$ das crianças do Grupo 2, e 38\% das do Grupo 3. Quanto ao desempenho superior, o Grupo 1 apresentou 14\% de crianças nessa condição, o Grupo 2, $60 \%$ e o Grupo 3, 24\%. O Grupo 3 obteve índices maiores que os demais grupos com desempenho médio. Para os três grupos, o melhor desempenho foi observado no subteste de leitura e o pior em aritmética. 
Figura 1 - Porcentagem de participantes segundo o desempenho obtido no TDE nos itens avaliados

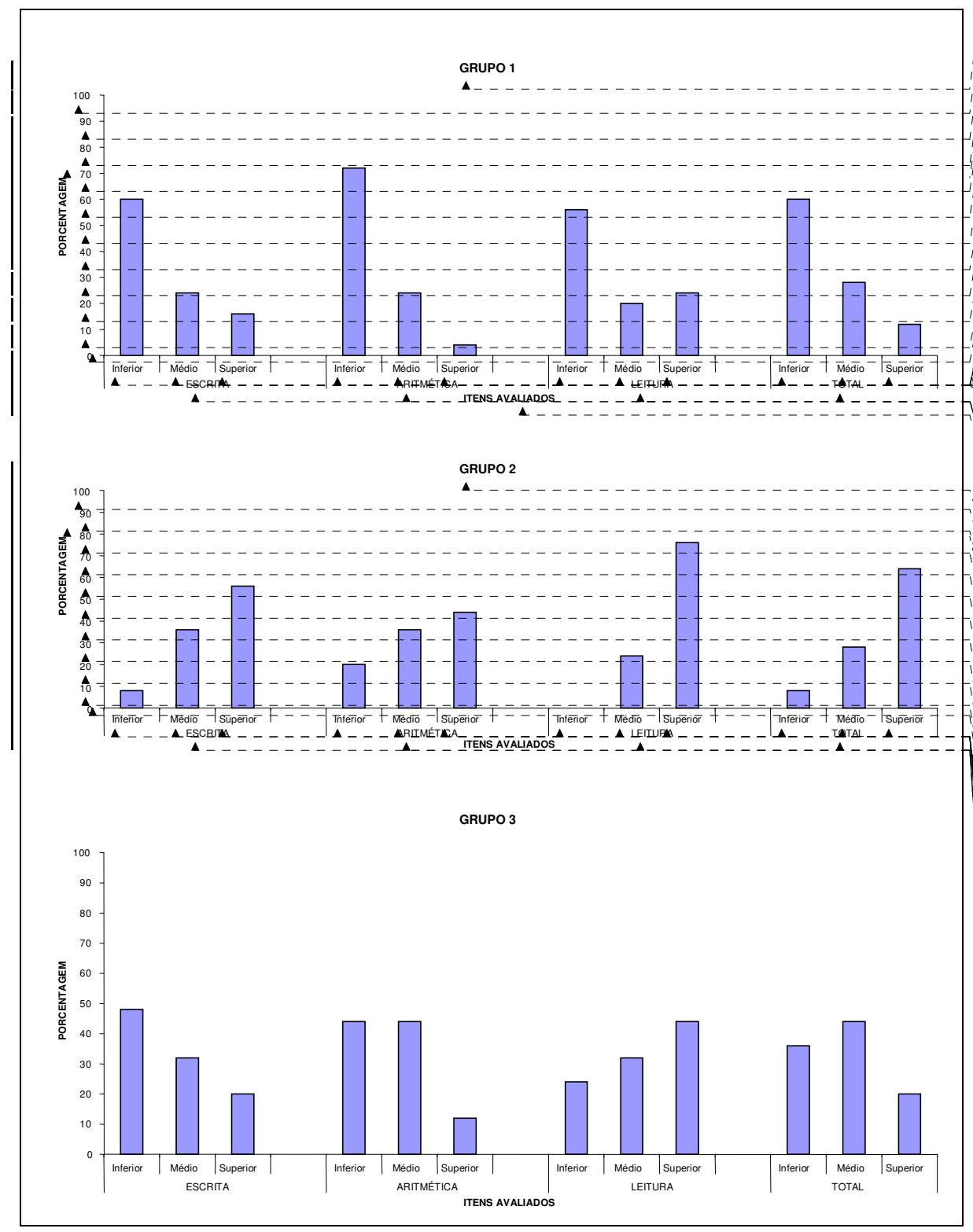

\begin{tabular}{|c|c|}
\hline Formatado & $\ldots[1]$ \\
\hline Formatado & $\ldots[2]$ \\
\hline Formatado & $\ldots[3]$ \\
\hline Formatado & $\ldots[4]$ \\
\hline Formatado & $\ldots[5]$ \\
\hline Formatado & $\ldots[6]$ \\
\hline Formatado & ... [7] \\
\hline Formatado & $\ldots[8]$ \\
\hline Formatado & $\ldots[9]$ \\
\hline Formatado & $\ldots[10]$ \\
\hline Formatado & $\ldots[11]$ \\
\hline Formatado & $\ldots[12]$ \\
\hline Formatado & $\ldots[13]$ \\
\hline Formatado & $\ldots[14]$ \\
\hline Formatado & $\ldots[15]$ \\
\hline Formatado & $\ldots[16]$ \\
\hline Formatado & $\ldots[17]$ \\
\hline Formatado & $\ldots[18]$ \\
\hline Formatado & $\ldots[19]$ \\
\hline Formatado & $\ldots[20]$ \\
\hline Formatado & $\ldots[21]$ \\
\hline Formatado & $\ldots[22]$ \\
\hline Formatado & $\ldots[23]$ \\
\hline Formatado & $\ldots[24]$ \\
\hline Formatado & $\ldots[25]$ \\
\hline Formatado & $\ldots[26]$ \\
\hline Formatado & $\ldots[27]$ \\
\hline Formatado & $\ldots[28]$ \\
\hline Formatado & $\ldots[29]$ \\
\hline Formatado & $\ldots[30]$ \\
\hline Formatado & $\ldots[31]$ \\
\hline Formatado & $\ldots[32]$ \\
\hline Formatado & $\ldots$ [33] \\
\hline Formatado & $\ldots$ [34] \\
\hline Formatado & $\ldots[35]$ \\
\hline Formatado & $\ldots[36]$ \\
\hline Formatado & $\ldots$ [37] \\
\hline Formatado & $\ldots[38]$ \\
\hline Formatado & ... [39] \\
\hline Formatado & $\ldots[40]$ \\
\hline Formatado & $\ldots[41]$ \\
\hline Formatado & $\ldots[42]$ \\
\hline Formatado & ... [43] \\
\hline Formatado & ... [44] \\
\hline Formatado & $\ldots[45]$ \\
\hline Formatado & $\ldots[46]$ \\
\hline Formatado & $\ldots$ [47] \\
\hline Formatado & $\ldots[48]$ \\
\hline Formatado & $\ldots[49]$ \\
\hline Formatado & $\ldots[50]$ \\
\hline Formatado & $\ldots[51]$ \\
\hline Formatado & $\ldots[52]$ \\
\hline Formatado & $\ldots[53]$ \\
\hline Formatado & $\ldots[54]$ \\
\hline Formatado & $\ldots[55]$ \\
\hline Formatado & $\ldots[56]$ \\
\hline Formatado & $\ldots[57]$ \\
\hline Formatado & $\ldots[58]$ \\
\hline Formatado & . [59] \\
\hline
\end{tabular}


Os resultados confirmam os de Banks, Ferretti e Shuccard (1997), os de Moreira e Moreira (2004) e os de Bellinger (1995) que, apesar de não terem avaliado o desempenho escolar, mostram que a diminuição da inteligência é um dos efeitos prováveis do chumbo, diretamente envolvida no rendimento escolar de crianças.

Observando que pesquisadores (Needleman et al., 1979; Yule et al., 1981; Silbergeld, 1997) chamaram a atenção para o fato de que as populações contaminadas por chumbo também sofriam a influência de outras variáveis, como pobreza, pouca estimulação ambiental, baixa escolaridade dos pais, optou-se por um procedimento experimental que controlasse tais variáveis. Comparando grupos de crianças com as mesmas características, este estudo tinha como objetivo mostrar o efeito do chumbo no desempenho escolar. Os dados obtidos indicam que os baixos resultados obtidos pelo grupo de crianças contaminadas podem ser atribuídos ao chumbo.

Uma análise mais detalhada foi feita, comparando os desempenhos das meninas e dos meninos em cada uma das áreas avaliadas.

De acordo com a figura 2, o desempenho dos meninos do grupo com chumbo zero, em relação à escrita, foi melhor do que o das meninas. Os meninos do grupo controle apresentam desempenho inferior às meninas do mesmo grupo, assim como os meninos do grupo de crianças contaminadas. Todavia, as crianças contaminadas, principalmente os meninos, apresentaram o pior desempenho em escrita.

Figura 2 - Freqüência do desempenho no TDE, em escrita, para meninos e meninas

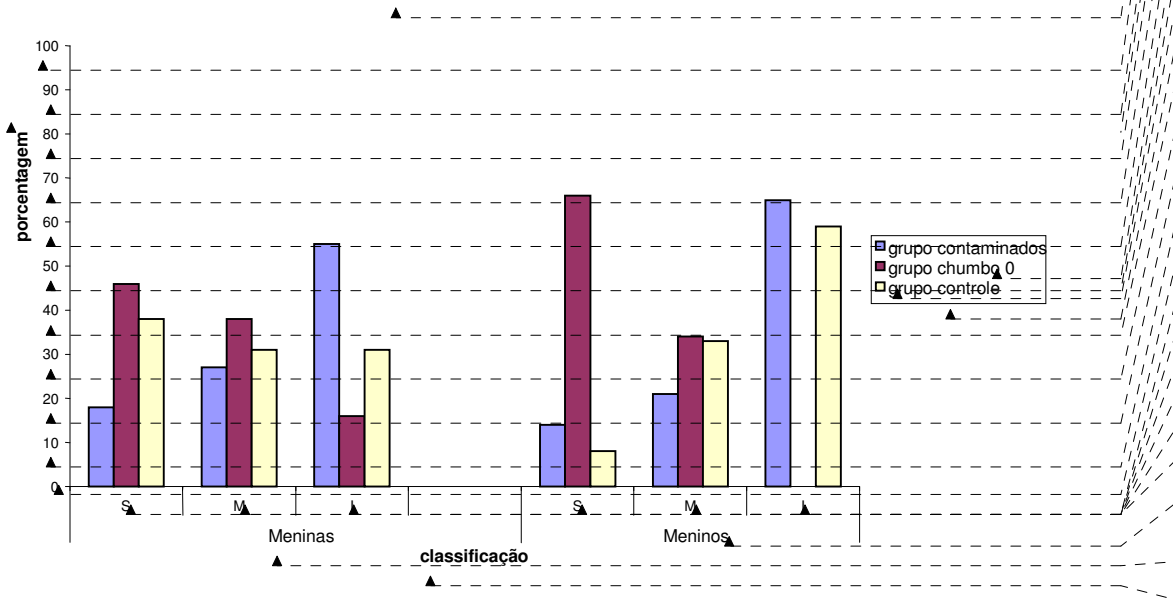

Estudos em Avaliação Educacional, v. 19, n. 39, jan./abr. 2008
169

\begin{tabular}{|l|}
\hline Formatado: Fonte: $8,5 \mathrm{pt}$ \\
\hline Formatado: Fonte: $8,5 \mathrm{pt}$ \\
\hline Formatado: Fonte: $8,5 \mathrm{pt}$ \\
\hline Formatado: Fonte: $5,5 \mathrm{pt}$ \\
\hline Formatado: Fonte: $8,5 \mathrm{pt}$ \\
\hline Formatado: Fonte: $8,5 \mathrm{pt}$ \\
\hline Formatado: Fonte: $8,5 \mathrm{pt}$ \\
\hline Formatado: Fonte: $5,5 \mathrm{pt}$ \\
\hline Formatado: Fonte: $8,5 \mathrm{pt}$ \\
\hline Formatado: Fonte: $5,5 \mathrm{pt}$ \\
\hline Formatado: Fonte: $5,5 \mathrm{pt}$ \\
\hline Formatado: Fonte: $8,5 \mathrm{pt}$ \\
\hline Formatado: Fonte: $8,5 \mathrm{pt}$ \\
\hline Formatado: Fonte: $8,5 \mathrm{pt}$ \\
\hline Formatado: Fonte: $8,5 \mathrm{pt}$ \\
\hline Formatado: Fonte: $8,5 \mathrm{pt}$ \\
\hline Formatado: Fonte: $8,5 \mathrm{pt}$ \\
\hline Formatado: Fonte: $8,5 \mathrm{pt}$ \\
\hline Formatado: Fonte: $8,5 \mathrm{pt}$ \\
\hline Formatado: Fonte: $8,5 \mathrm{pt}$ \\
\hline Formatado: Fonte: $8,5 \mathrm{pt}$ \\
\hline Formatado: Fonte: $8,5 \mathrm{pt}$ \\
\hline Formatado: Fonte: $(\mathrm{Padra}$ ) \\
\hline Formatado: Fonte: $5,5 \mathrm{pt}$ \\
\hline
\end{tabular}


Em aritmética, como mostra a figura 3, as crianças do Grupo 1 (contaminadas), independentemente do gênero, apresentaram o pior desempenho; porém, ainda assim, o pior resultado foi o das meninas. As meninas do Grupo 2 (com chumbo zero) foram melhores do que os meninos. No Grupo 3, os meninos foram melhores do que as meninas.

\section{Figura 3 - Freqüência do desempenho no TDE, em aritmética, para} meninos e meninas

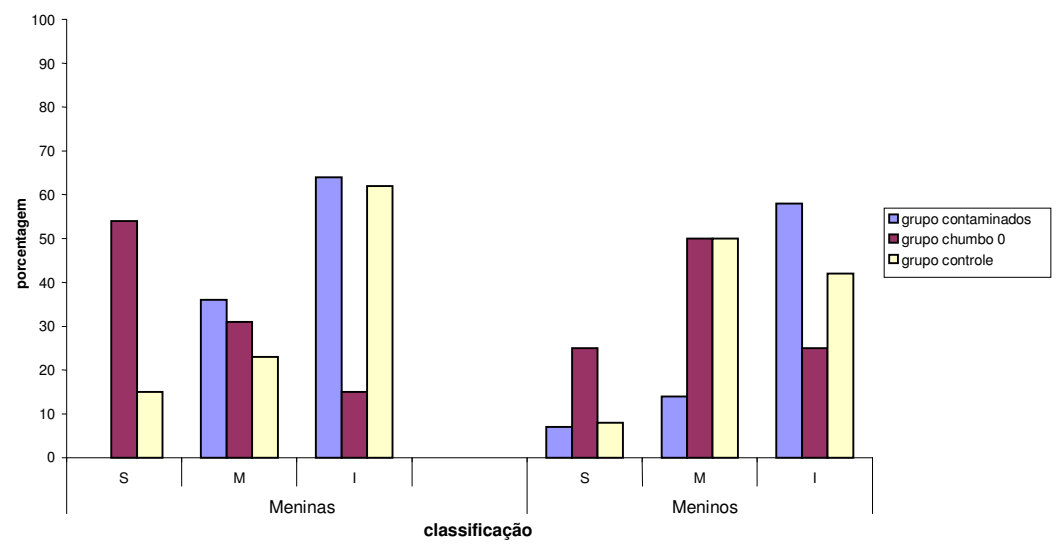

As meninas dos Grupos 2 e 3 (com chumbo zero e de controle), em leitura, apresentaram, igualmente, um bom desempenho. Ainda que as meninas contaminadas tenham tido um desempenho melhor que os meninos desse grupo, elas se saíram pior que as demais, assim como os meninos. Nesse item o melhor foi o Grupo 2 (crianças com chumbo zero) (Figura 4). 
Figura 4 - Freqüência do desempenho no TDE, em leitura, para meninos e meninas

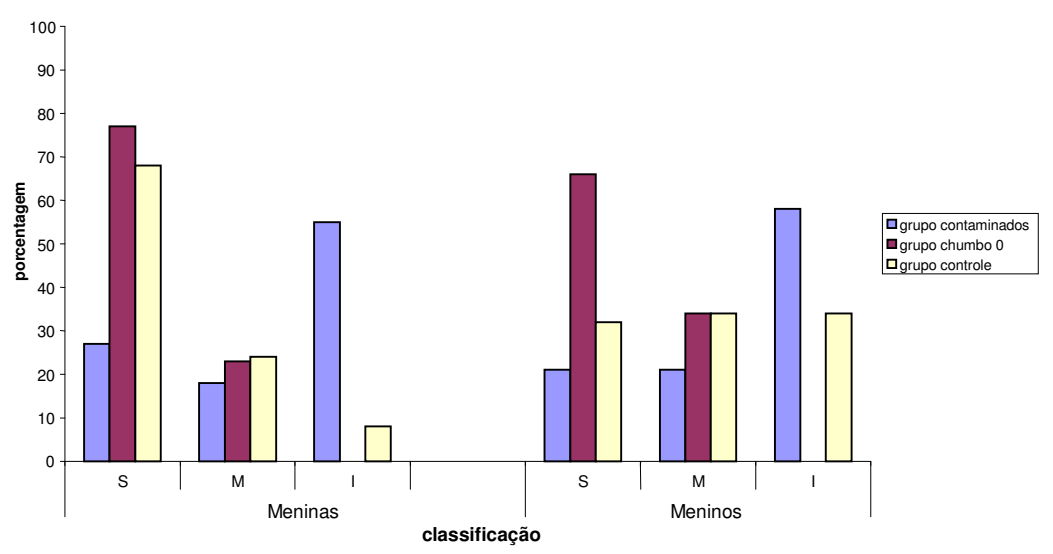

Figura 5 - Freqüência do desempenho global no TDE, para meninos e meninas

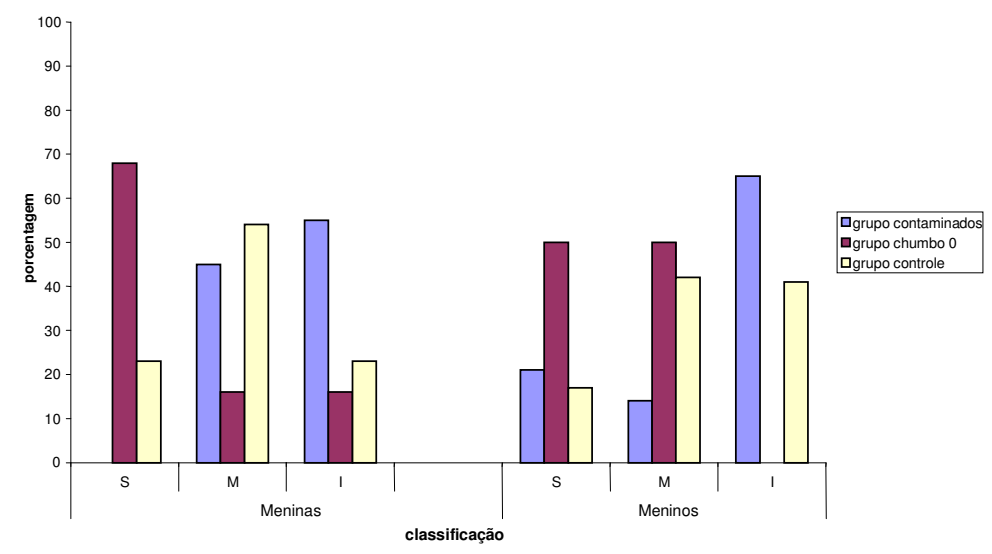


Considerando o desempenho geral no TDE, observamos que tanto os meninos quanto as meninas do Grupo 2 (chumbo zero) foram os melhores; porém, as meninas se sobressaíram. O mesmo se observa com o Grupo 3, apesar do desempenho médio. Para o Grupo 1, as meninas se dividiram em desempenho médio e inferior, enquanto a maioria dos meninos apresentou desempenho inferior (Figura 5).

Em relação às diferenças entre gêneros, percebe-se que o grupo feminino teve um desempenho melhor no TDE, no geral e nos itens de escrita e leitura. Em aritmética, os meninos foram melhores. Outros pesquisadores (Carvalho, 2001, 2003; Silva et al., 1999; Rosemberg, 1992, 2001) também apontaram que as meninas têm desempenho escolar melhor que os meninos.

Carvalho (2001) constata, em seu estudo, sensível diferença em favor das meninas no desempenho escolar, principalmente em Português e Linguagem. Já em Matemática, nota-se que o desempenho dos meninos e meninas, no início, é semelhante, mas vai se diferenciando em favor dos meninos à medida ascendem no sistema escolar. No presente estudo, os dados obtidos confirmam esses resultados.

Ainda que o Grupo 1 (crianças contaminadas) tenha apresentado desempenho inferior aos demais grupos, observou-se diferença, também, entre as crianças dos Grupos 2 e 3 (com chumbo zero e de controle). As crianças dos Grupos 1 e 2 freqüentavam as mesmas escolas (pelo menos quatro das seis escolas eram comuns aos dois grupos) e viviam no mesmo bairro, enquanto as crianças do Grupo 3 não. Eram todos oriundos de escolas públicas estaduais (Grupos 1, 2 e 3) e uma municipal (Grupos 1 e 2), as quais tinham autonomia na construção do projeto pedagógico, norteado pelos parâmetros nacionais da educação, não sendo possível, assim, controlar essa variável com segurança. Uma possibilidade seria creditar os resultados diferenciados à prática pedagógica a que estariam expostas as crianças dos três grupos. Analisou-se, então, o desempenho dos grupos, considerando a escola que freqüentavam.

Como nos mostra a tabela 3, os alunos avaliados estavam distribuídos em sete escolas. A escola municipal tinha crianças com e sem contaminação. No Grupo 1, dessa escola, apenas uma criança teve desempenho inferior (6\%) enquanto a maioria do Grupo 2 apresentou desempenho superior (58\%). 
Tabela 3 - Distribuição dos alunos participantes por escola

\begin{tabular}{|c|c|c|c|c|c|c|c|c|c|c|}
\hline \multirow{2}{*}{ Escolas } & \multicolumn{3}{|c|}{ Grupo 1} & \multicolumn{3}{|c|}{ Grupo 2} & \multicolumn{3}{|c|}{ Grupo 3} & \multirow{2}{*}{ Total } \\
\hline & Inferior & Médio & Superior & Inferior & Médio & Superior & Inferior & Médio & Superior & \\
\hline A municipal & 1 & 2 & 1 & - & 4 & 11 & - & - & - & 19 \\
\hline B estadual & 1 & - & - & - & 1 & 1 & - & - & - & 3 \\
\hline C estadual & - & - & & 3 & 1 & 3 & - & - & - & 7 \\
\hline D estadual & 4 & 1 & - & - & - & - & - & - & - & 5 \\
\hline E estadual & 5 & 4 & 1 & & 1 & - & - & - & - & 11 \\
\hline F estadual & 4 & - & & & 1 & - & & - & - & 5 \\
\hline G estadual & - & - & - & - & - & - & 9 & 11 & 5 & 25 \\
\hline Total & 15 & 4 & 2 & 3 & 8 & 15 & 9 & 11 & 5 & 75 \\
\hline
\end{tabular}

Levando em conta que as condições sociais e culturais dos grupos eram muito parecidas, é possível que a estimulação ambiental advinda da exposição das crianças a práticas educativas favoráveis tenha influenciado os resultados obtidos pelas crianças do Grupo 2. Tais dados parecem confirmar os achados de Berry (2002) que enfatiza a importância da estimulação ambiental para superar os efeitos da contaminação por chumbo. $\mathrm{O}$ autor relata uma ligação clara entre qualidade ambiental das escolas e desempenho educacional, num estudo conduzido em uma escola primária de Washington (EUA). A performance de crianças contaminadas por chumbo melhorou muito quando houve: gestão participativa; integração com a comunidade; atitudes positivas para a aprendizagem; respeito às diferenças individuais; reconhecimento e valorização da diversidade, como elemento natural e enriquecedor do processo escolar; professores conscientes do modo como atuam, para promover a aprendizagem de todos os alunos; cooperação entre os implicados no processo educativo, dentro e fora da escola; valorização do processo sobre o produto da aprendizagem; tempo para aprender e enfoques curriculares e metodológicos que visam e propiciam a construção coletiva do conhecimento.

Em razão da dificuldade em acabar com as exposições globais ao chumbo, a curto e médio prazo, muito deve ser feito para localizar populações de risco, e, assim, alterar ciclos de contaminação que, Estudos em Avaliação Educacional, v. 19, n. 39, jan./abr. 2008 
porventura, possam estar se perpetuando. Dentre as várias intervenções internacionais que podem diminuir sua utilização e exposição, estão: remoção do chumbo do petróleo, de aditivos, tintas, vasilhas de estocagem de alimentos, cosméticos e medicamentos; diminuição da dissolução de chumbo nos sistemas de tratamento e distribuição de água e melhora do controle nos locais de trabalho, por meio de fiscalizações mais sérias. Também é importante: monitorar as populações de risco; implementar procedimentos preventivos mediante a educação da população e promover programas que visem à diminuição da desnutrição e de outros fatores que agravem a intoxicação por chumbo (World..., 1989; Chung et al., 2001; Hynes et al., 2001).

\section{CONSIDERAÇÕES FINAIS}

Concernentes com a literatura, não podemos negar os efeitos do chumbo; porém estudos visando a acompanhar o desempenho escolar das crianças contaminadas, inexistentes no Brasil, são necessários, pois outras variáveis (orgânicas, ambientais e sociais) podem estar minimizando ou acentuando esses efeitos, uma vez que o chumbo age de forma diferente em cada indivíduo.

Desse modo, consideramos que, com base nos resultados obtidos, outras investigações e intervenções poderiam ser feitas, visto que na escola onde os alunos não foram submetidos ao exame de sangue, o desempenho também foi aquém do esperado. Portanto, para maior confiabilidade dos dados, todos os alunos participantes poderiam ser submetidos ao exame de sangue, para verificar a presença ou não de chumbo acima do tolerável. Além dessa providência, uma observação mais sistemática da prática pedagógica de todas as escolas envolvidas poderia contribuir para a implementação de programas de formação continuada de professores.

Pensando também na integração com a comunidade, as escolas deveriam organizar reuniões com os pais dos alunos avaliados, para serem orientados de como estimular o desenvolvimento de seus filhos, com a finalidade de minimizar os atrasos apresentados. Um ambiente estimulante pode reverter os prejuízos ocasionados pelo chumbo e ajudar a superar o déficit de aprendizagem, uma vez que o metal afeta os processos cognitivos e a atenção, condição básica para o desempenho acadêmico. É necessário acabar com a situação de pobreza e miséria em que muitas de nossas crianças vivem, ficando, assim, menos propensas aos efeitos de qualquer contaminação ambiental a que forem expostas. 


\section{REFERÊNCIAS BIBLIOGRÁFICAS}

ACEITUNO, J. Já são 76 crianças contaminadas por chumbo em Bauru. $O$ Estado de S. Paulo. São Paulo, 18 abr. 2002.

ARAUJO, U.; PIVETTA, F.; MOREIRA, J. C. Avaliação da exposição ocupacional ao chumbo: proposta de uma estratégia de monitoramento para prevenção dos efeitos clínicos e subclínicos. Cad. Saúde Pública, v. 15, n.1, p. 123-132, jan./mar. 1999.

BANKS, E. C.; FERRETTI, L. E.; SHUCARD, D. W. Effects of low level lead exposure on cognitive function in children: a review of behavioral, neuropsychological and biological evidence. Neurotoxicology, v. 18, n.1, p. 237-282, 1997.

BELLINGER, D. C. Interpreting the literature on lead and child development: the neglected role of the experimental system. Neurotoxicology and Teratology, v. 17, n. 3, p. 201-212, 1995.

BELLINGER, D. C. et al. A Pilot study of blood levels and neurobehavioral function in children living in Chennai, India. International Journal of Occupational and Environmental Health, v. 11, n. 2, p. 138-143, 2005.

BERRY, M. Healthy School Environment and Enhanced Educational Performance. The Case of Charles Young Elementary School. Washington, D. C. Principal Investigator. 12, Jan. 2002.

CAMPANILI, M. Apenas $22 \%$ dos resíduos industriais têm tratamento adequado. O Estado de S. Paulo, São Paulo, 2 mai. 2002.

CANFIELD, R. L. et al. Intellectual impairment in children with blood lead concentrations below 10 microg per deciliter. $N$ Engl J Med, v. 348, n. 16, p. 1517-1526, 2003.

CARVALHO, M. P. Mau aluno, boa aluna? Como as professoras avaliam meninos e meninas. Estudos Feministas, v. 9, n. 2, p. 554-574, dez. 2001.

Sucesso e fracasso escolar: uma questão de gênero. Educação $e$ Pesquisa. v. 29, n.1, jan./jun. 2003. 
CHUNG, E. K. et al. A Comparision of elevated blood lead levels among children living in foster care, their siblings and general population. Pediatrics, v. 107, n. 5, 2001.

CORDEIRO, R. O saturnismo em Bauru. In: PIMENTA, A. L. ; COSTA FILHO, D. C. (org.) Saúde do Trabalhador. São Paulo: Hucitec, 1988. p. 47-83

CORDEIRO, R.; LIMA-FILHO, E. C. A Inadequação dos valores dos limites de tolerância biológica para a prevenção da intoxicação profissional pelo chumbo no Brasil. Cadernos de Saúde Pública. v. II, n. 2, abr./jun. 1995.

DIAS, T. L.; ENUMO, S. R. F.; AZEVEDO JUNIOR, R. R. Influências de um programa de criatividade no desempenho cognitivo e acadêmico de alunos com dificuldade de aprendizagem. Psicol. estud., v. 9, n. 3, p. 429-437, dez. 2004.

ERICKSON, M. F.; RIEMER, K. Infant Toddlers and families: a framework for support and intervention. New York: The Guilford Press, 1999.

FONSECA, L. C. et al. Desempenho escolar em crianças com epilepsia benigna da infância com pontas centrotemporais. Arq. Neuro-Psiquiatr., v.62, n. 2b, p. 459-462, jun. 2004.

Eletroencefalograma quantitativo em escolares sadios: análise de frequências. Arq. Neuro-Psiquiatr., v. 61, n. 3B, p. 796-801, set. 2003.

GIBSON, J. L. et al. Note on lead poisoning as observed among children in Brisbane. Proceedings of the Third Intercolonial Medical Congress. Sydney, Australia, 1892. p. 76-83

GIDLOW, D. A. Lead toxicity. Occupational Medicine, v. 54, p. 76-81, 2004.

GOMES, Jorge da Rocha. Doenças causadas por chumbo e seus compostos. Disponível em: http://www.geocities.com/Athens/Troy/8084/ chumb.htm. Acesso em: 12 fev. 2003.

GUAIUME, S. Relatório comprova: moradores de Paulínia estão contaminados. Jornal da Tarde. São Paulo, 22 ago. 2001.

GURALNICK, M. J. The effectiveness of early intervention. Baltimore: Paul H. Brookes, 1997. 
HARVEY, P.; HAMLIN, N.; KUMAR, R. The Birmingham blood lead study. Paper presented at the Annual Conference of the Bristish Psychological Society. April,1983.

HYNES, H. P. et al. Dorchester Lead-Safe Yard project: a pilot program to demonstrate low-cost, onsite techniques to reduce exposure to leadcontaminated soil. J. Urban Health, v. 78, n. 1, p. 199-211, 2001.

INTERNATIONAL PROGRAMME ON CHEMICAL SAFETY - IPCS, 1995. Environmental Health Criteria 165 for Inorganic Lead. In: GURALNICK, M. J. The effectiveness of early intervention. Baltimore: Paul H. Brookes, 1997.

KOLLER, K. et al. Recent developments in low-level lead exposure and intellectual impairment in children. Environ Health Perspect. Weston Parkway, USA, n. 112, p. 987-994, 2004.

LARINI, L. Toxicologia. 2. ed. São Paulo: Manole, 1993.

MALTA, C. G. T.; TRIGO, L. A. S. C.; CUNHA, L. S. Saturnismo. Disponível em: http://www.geocities.com/HotSprings/Resort/4486/ chumbo1.htm., 2000. Acesso em: 7 set. 2002.

MAVROPOULOS, E. A Hidroxiapatita como absorvedor de metais. Rio de Janeiro, 1999. Dissertação (mestr.) Fundação Oswaldo Cruz, Escola Nacional de Saúde Pública. 105 p.

MEIRELES, H. L. Direito Municipal Brasileiro. 4. ed. São Paulo, Revista dos Tribunais, 1981. $723 \mathrm{p}$.

MOREIRA, F. R.; MOREIRA, J. C. Os Efeitos do chumbo sobre o organismo humano e seu significado para a saúde. Panam Salud Publica, v. 15, n. 2, p. 119-29, 2004.

NEEDLEMAN, H. L. Lead levels and children's psychologic performance. New England Journal of Medicine, v. 301, n. 3, p. 163, 1979.

NEEDLEMAN, H. ; GATSONIS, C. Exposição de ligação de baixo nível e o QI das crianças. Jornal da Associação Médica Americana, v. 263, p. 673-678, 1990. 
PADULA, N. A. M. R. et al. Intoxicação por chumbo e saúde infantil: ações intersetoriais para o enfrentamento da questão. Cadernos de Saúde Pública, v. 22, n. 1, p. 163-171, 2006.

ROCHA, L. A. R.; HORTA, G. O. Avaliação da intoxicação profissional por chumbo em indústrias de acumuladores elétricos na Grande Belo Horizonte. Revista Brasileira de Saúde Ocupacional, n. 15 p. 6-12. 1987.

RODRIGUES, O. M. P. R. Atendimento emergencial de crianças de zero a 12 anos contaminadas por chumbo. Projeto de Extensão. Bauru: Proex/Unesp, 2002.

ROSEMBERG, F. Educação formal e mulher: um balanço parcial. In: COSTA, A. de O.; BRUSCHINI, C. (orgs.). Uma Questão de gênero. Rio de Janeiro: Rosa dos Tempos; São Paulo: Fundação Carlos Chagas, 1992.

Educação formal, mulher e gênero no Brasil contemporâneo. Estudos Feministas, v. 9, n. 2, 2001.

SALVIA, J.; YSSELDYKE, J. E. Avaliação em Educação Especial e Corretiva. São Paulo: Editora Manole, 1991.

SÃO PAULO. Manuais de Legislação Atlas: Segurança e Medicina do Trabalho. 36. ed., v. 16, São Paulo: Atlas, 1997.

SILBERGELD, E. K. Preventing lead poisoning in children. Annu Rev Public Health, v. 18, p. 187-210, 1997.

SILVA, C. D. da et al. Meninas bem comportadas, boas alunas; meninos inteligentes, indisciplinados. Cadernos de Pesquisa, n. 107, p. 207-225, jul. 1999.

SIMONETTI, M. et al. Investigação epidemiológica de exposição ao chumbo proveniente de empresa de acumuladores e baterias em Bauru. In: EXPOEPI, 3. Mostra Nacional de Experiências Bem Sucedidas em Epidemiologia, Prevenção e Controle de Doenças. Anais do... São Paulo, 2004. p. $72-81$

SMITH, M. Recent work on low level lead exposure and its impact on behavior, intelligence, and learning: uma revisão. Journal of the American Academy of Child Psychiatry, n. 24, p. 1-32, 1985. 
STEIN, L. M. Teste de Desempenho Escolar - TDE. São Paulo: Casa do Psicólogo, 1994.

STILES, K.; BELLINGER, D. C. Neuropsychological correlates of low-level lead exposure in school-age children: a prospective study. Neurotoxicology and Teratology, n. 15, p. 27-35, 1993.

TESMAN, J. R.; HILLS, A. Developmental effects of lead exposure in children. Social Policy Report, Society for Research in Child Development, v. 8, n. 3, p. 1-16, 1994.

THACKER, S. B. et al. Reply: effect of low-level body burdens of lead on the mental development of children. Arch Environ Health, n. 49, p. 204-205, 1992.

THATCHER, R. W. et al. Effects of low levels of cadmium and lead on cognitive functioning in children. Archives of Environmental Health, v. 37, n. 3, p. 159-166, 1982.

THOMSON, G. O. B. et al. Blood-lead levels and children's behavior: results from the Edinburgh lead study. Journal of Child Psychology and Psychiatry, n. 30, p. 515-528, 1989.

VEGA-DIENSTMAIER, J. M. et al. Lead levels and cognitive abilities in peruvian children. Rev. Bras. Psiquiatr., v. 28, n. 1, p. 33-39, mar. 2006.

WORLD HEALTH ORGANIZATION. United Nations Environment Programme, International Labour Organization \& World Health Organization. Lead - Environment Aspects. Environment Health Criteria 85. International Programme on Chemical Safety, Geneva, 1989.

YULE, W.; RUTTER, M. Effect of lead on children's behavior and cognitive performance: a critical review. In: MAHAFFEY, K. R. (ed.). Dietary and Environmental Lead: human health effects. Amsterdam: Elsevier, New York: Oxford, p. 211-259, 1983.

YULE, W. et al. The relationship between blood lead concentrations, intelligence and attainment in a school population: a pilot study. Develop. Med. Child Neurol. Dallas, USA, n. 23, p. 567-576, 1981. 
ZANOTI-JERONYMO, D. V.; CARVALHO, A. M. P. Self-concept, academic performance and behavioral evaluation of the children of alcoholic parents. Rev. Bras. Psiquiatr., v. 27, n. 3, p. 233-236, Sept. 2005.

Recebido em: maio 2007

Aprovado para publicação em: agosto 2007 


\begin{tabular}{|c|c|c|}
\hline Página 168: [1] Formatado & cmoraes & $19 / 03 / 2008$ 12:42:00 \\
\hline \multicolumn{3}{|l|}{ Fonte: $14 \mathrm{pt}$} \\
\hline Página 168: [2] Formatado & cmoraes & $19 / 03 / 2008$ 12:43:00 \\
\hline \multicolumn{3}{|l|}{ Fonte: $14 \mathrm{pt}$} \\
\hline Página 168: [3] Formatado & cmoraes & 19/03/2008 12:43:00 \\
\hline \multicolumn{3}{|l|}{ Fonte: $14 \mathrm{pt}$} \\
\hline Página 168: [4] Formatado & cmoraes & 19/03/2008 12:43:00 \\
\hline \multicolumn{3}{|l|}{ Fonte: $14 \mathrm{pt}$} \\
\hline Página 168: [5] Formatado & cmoraes & $19 / 03 / 2008$ 12:43:00 \\
\hline \multicolumn{3}{|l|}{ Fonte: $4 \mathrm{pt}$} \\
\hline Página 168: [6] Formatado & cmoraes & $19 / 03 / 200812: 43: 00$ \\
\hline \multicolumn{3}{|l|}{ Fonte: $14 \mathrm{pt}$} \\
\hline Página 168: [7] Formatado & cmoraes & $19 / 03 / 200812: 43: 00$ \\
\hline \multicolumn{3}{|l|}{ Fonte: $14 \mathrm{pt}$} \\
\hline Página 168: [8] Formatado & cmoraes & $19 / 03 / 200812: 43: 00$ \\
\hline \multicolumn{3}{|l|}{ Fonte: $14 \mathrm{pt}$} \\
\hline Página 168: [9] Formatado & cmoraes & 19/03/2008 12:43:00 \\
\hline \multicolumn{3}{|l|}{ Fonte: $14 \mathrm{pt}$} \\
\hline Página 168: [10] Formatado & cmoraes & $19 / 03 / 200812: 43: 00$ \\
\hline \multicolumn{3}{|l|}{ Fonte: $14 \mathrm{pt}$} \\
\hline Página 168: [11] Formatado & cmoraes & $19 / 03 / 200812: 43: 00$ \\
\hline \multicolumn{3}{|l|}{ Fonte: $14 \mathrm{pt}$} \\
\hline Página 168: [12] Formatado & cmoraes & $19 / 03 / 200812: 43: 00$ \\
\hline \multicolumn{3}{|l|}{ Fonte: $14 \mathrm{pt}$} \\
\hline Página 168: [13] Formatado & cmoraes & $19 / 03 / 200812: 43: 00$ \\
\hline \multicolumn{3}{|l|}{ Fonte: $14 \mathrm{pt}$} \\
\hline Página 168: [14] Formatado & cmoraes & $19 / 03 / 200812: 42: 00$ \\
\hline \multicolumn{3}{|l|}{ Fonte: $14 \mathrm{pt}$} \\
\hline Página 168: [15] Formatado & cmoraes & $19 / 03 / 200812: 42: 00$ \\
\hline \multicolumn{3}{|l|}{ Fonte: $14 \mathrm{pt}$} \\
\hline Página 168: [16] Formatado & cmoraes & $19 / 03 / 2008$ 12:42:00 \\
\hline \multicolumn{3}{|l|}{ Fonte: $14 \mathrm{pt}$} \\
\hline Página 168: [17] Formatado & cmoraes & $19 / 03 / 200812: 42: 00$ \\
\hline \multicolumn{3}{|l|}{ Fonte: $14 \mathrm{pt}$} \\
\hline Página 168: [18] Formatado & cmoraes & $19 / 03 / 200812: 42: 00$ \\
\hline \multicolumn{3}{|l|}{ Fonte: $14 \mathrm{pt}$} \\
\hline Página 168: [19] Formatado & cmoraes & $19 / 03 / 200812: 42: 00$ \\
\hline \multicolumn{3}{|l|}{ Fonte: $14 \mathrm{pt}$} \\
\hline Página 168: [20] Formatado & cmoraes & $19 / 03 / 200812: 42: 00$ \\
\hline \multicolumn{3}{|l|}{ Fonte: $14 \mathrm{pt}$} \\
\hline Página 168: [21] Formatado & cmoraes & $19 / 03 / 200812: 42: 00$ \\
\hline \multicolumn{3}{|l|}{ Fonte: $14 \mathrm{pt}$} \\
\hline Página 168: [22] Formatado & cmoraes & $19 / 03 / 2008$ 12:42:00 \\
\hline \multicolumn{3}{|l|}{ Fonte: $14 \mathrm{pt}$} \\
\hline Página 168: [23] Formatado & cmoraes & $19 / 03 / 2008$ 12:42:00 \\
\hline
\end{tabular}

Fonte: $14 \mathrm{pt}$ 
Página 168: [24] Formatado

Fonte: $14 \mathrm{pt}$

\begin{tabular}{|c|c|c|}
\hline \multicolumn{3}{|l|}{$\begin{array}{l}\text { Página 168: [25] Formatado } \\
\text { Fonte: } 4 \mathrm{pt}\end{array}$} \\
\hline Página 168: [26] Formatado & cmoraes & 19/03/2008 12:42:00 \\
\hline \multicolumn{3}{|l|}{ Fonte: $14 \mathrm{pt}$} \\
\hline \multicolumn{2}{|l|}{ Fonte: $14 \mathrm{pt}$} & 19/03/2008 12:42:00 \\
\hline \multicolumn{3}{|l|}{ Fonte: $14 \mathrm{pt}$} \\
\hline \multicolumn{2}{|l|}{ Fonte: $14 \mathrm{pt}$} & 19/03/2008 12:42:00 \\
\hline $\begin{array}{l}\text { Página 168: [30] Formatado } \\
\text { Fonte: } 14 \mathrm{pt}\end{array}$ & cmoraes & 19/03/2008 12:42:00 \\
\hline \multicolumn{3}{|l|}{ Fonte: $16 \mathrm{pt}$} \\
\hline $\begin{array}{l}\text { Página 168: [32] Formatado } \\
\text { Fonte: } 14 \mathrm{pt}\end{array}$ & cmoraes & 19/03/2008 12:40:00 \\
\hline $\begin{array}{l}\text { Página 168: [33] Formatado } \\
\text { Fonte: } 14 \mathrm{pt}\end{array}$ & cmoraes & 19/03/2008 12:41:00 \\
\hline $\begin{array}{l}\text { Página 168: [34] Formatado } \\
\text { Fonte: } 4 \mathrm{pt}\end{array}$ & cmoraes & 19/03/2008 12:41:00 \\
\hline
\end{tabular}

\begin{tabular}{|c|c|c|}
\hline Página 168: [35] Formatado & cmoraes & $19 / 03 / 200812: 40: 00$ \\
\hline \multicolumn{3}{|l|}{ Fonte: $14 \mathrm{pt}$} \\
\hline Página 168: [36] Formatado & cmoraes & $19 / 03 / 2008$ 12:41:00 \\
\hline \multicolumn{3}{|l|}{ Fonte: $14 \mathrm{pt}$} \\
\hline Página 168: [37] Formatado & cmoraes & $19 / 03 / 2008$ 12:41:00 \\
\hline \multicolumn{3}{|l|}{ Fonte: $14 \mathrm{pt}$} \\
\hline Página 168: [38] Formatado & cmoraes & $19 / 03 / 2008$ 12:41:00 \\
\hline \multicolumn{3}{|l|}{ Fonte: $14 \mathrm{pt}$} \\
\hline Página 168: [39] Formatado & cmoraes & $19 / 03 / 2008$ 12:41:00 \\
\hline \multicolumn{3}{|l|}{ Fonte: $14 \mathrm{pt}$} \\
\hline Página 168: [40] Formatado & cmoraes & $19 / 03 / 2008$ 12:41:00 \\
\hline \multicolumn{3}{|l|}{ Fonte: $14 \mathrm{pt}$} \\
\hline Página 168: [41] Formatado & cmoraes & $19 / 03 / 200812: 41: 00$ \\
\hline \multicolumn{3}{|l|}{ Fonte: $14 \mathrm{pt}$} \\
\hline Página 168: [42] Formatado & cmoraes & $19 / 03 / 200812: 41: 00$ \\
\hline \multicolumn{3}{|l|}{ Fonte: $14 \mathrm{pt}$} \\
\hline Página 168: [43] Formatado & cmoraes & $19 / 03 / 2008$ 12:41:00 \\
\hline \multicolumn{3}{|l|}{ Fonte: $14 \mathrm{pt}$} \\
\hline Página 168: [44] Formatado & cmoraes & $19 / 03 / 200812: 40: 00$ \\
\hline \multicolumn{3}{|l|}{ Fonte: $14 \mathrm{pt}$} \\
\hline Página 168: [45] Formatado & cmoraes & $19 / 03 / 2008$ 12:40:00 \\
\hline \multicolumn{3}{|l|}{ Fonte: $14 \mathrm{pt}$} \\
\hline Página 168: [46] Formatado & cmoraes & $19 / 03 / 200812: 39: 00$ \\
\hline
\end{tabular}


Fonte: $14 \mathrm{pt}$

\begin{tabular}{|c|c|c|}
\hline Página 168: [47] Formatado & cmoraes & $19 / 03 / 200812: 39: 00$ \\
\hline \multicolumn{3}{|l|}{ Fonte: $14 \mathrm{pt}$} \\
\hline Página 168: [48] Formatado & cmoraes & $19 / 03 / 200812: 39: 00$ \\
\hline \multicolumn{3}{|l|}{ Fonte: $14 \mathrm{pt}$} \\
\hline Página 168: [49] Formatado & cmoraes & 19/03/2008 12:39:00 \\
\hline \multicolumn{3}{|l|}{ Fonte: $14 \mathrm{pt}$} \\
\hline Página 168: [50] Formatado & cmoraes & 19/03/2008 12:39:00 \\
\hline \multicolumn{3}{|l|}{ Fonte: $14 \mathrm{pt}$} \\
\hline Página 168: [51] Formatado & cmoraes & 19/03/2008 12:39:00 \\
\hline \multicolumn{3}{|l|}{ Fonte: $14 \mathrm{pt}$} \\
\hline Página 168: [52] Formatado & cmoraes & 19/03/2008 12:38:00 \\
\hline \multicolumn{3}{|l|}{ Fonte: $4 \mathrm{pt}$} \\
\hline Página 168: [53] Formatado & cmoraes & $19 / 03 / 200812: 39: 00$ \\
\hline \multicolumn{3}{|l|}{ Fonte: $14 \mathrm{pt}$} \\
\hline Página 168: [54] Formatado & cmoraes & $19 / 03 / 200812: 44: 00$ \\
\hline \multicolumn{3}{|l|}{ Fonte: $14 \mathrm{pt}$} \\
\hline Página 168: [55] Formatado & cmoraes & $19 / 03 / 200812: 39: 00$ \\
\hline \multicolumn{3}{|l|}{ Fonte: $4 \mathrm{pt}$} \\
\hline Página 168: [56] Formatado & cmoraes & $19 / 03 / 200812: 40: 00$ \\
\hline \multicolumn{3}{|l|}{ Fonte: $14 \mathrm{pt}$} \\
\hline Página 168: [57] Formatado & cmoraes & 19/03/2008 12:39:00 \\
\hline \multicolumn{3}{|l|}{ Fonte: $14 \mathrm{pt}$} \\
\hline Página 168: [58] Formatado & cmoraes & $19 / 03 / 200812: 39: 00$ \\
\hline \multicolumn{3}{|l|}{ Fonte: $14 \mathrm{pt}$} \\
\hline Página 168: [59] Formatado & cmoraes & $19 / 03 / 200812: 39: 00$ \\
\hline Fonte: $14 \mathrm{pt}$ & & \\
\hline
\end{tabular}

